\title{
INFLUENCE OF DURATION AND INTENSITY OF WARM-UP SESSIONS ON THE PERFORMACE AMONG SHORT DISTANCE SWIMMERS
}

\author{
Goran Dimitrić, Miroslav Smajić and Đorđe Agbaba \\ Faculty of Sport and Physical Education, University of Novi Sad, Serbia
}

\begin{abstract}
It is well established that warm-up sessions are very important and essential part of every swimming competition. There is much evidence which tells how strong the influence of these sessions on swimming performance is. Although there are many suggestions about content of warm-up sessions in swimming, their duration and intensity, there are no clear conclusions about all segments of warm-up. Because of that many researchers tried to reveal how good warm-up sessions should look like. In this study 8 male and 4 female competitive swimmers aged 19 to 26 were tested. They were asked to swim three different warm-up sessions followed by 100 meters performance with maximal intensity. Before trial number 1 they performed long duration warmup session, before trial 2 short duration warm-up session and before trial 3 they were asked to perform warm-up session with high intensity. The recovery time between each warm-up session and the performance was 5 minutes and during these 5 minutes. ANOVA with Repeated Measures was used to test the differences in the performance that swimmers achieved after three different warm up sessions. Statistical significance was set at $p<0.05$. The results showed that there was not significant difference in the performance after long duration and short duration warm-up sessions $(\mathrm{p}=1)$. On the other hand the difference in the performance on the trial 1 and trial 3 was significant $(p=.02)$. Furthermore, the difference between trial 2 and trial 3 was significant as well $(\mathrm{p}=.03)$. Duration of the warm up session did not have significant influence on the performance. On the other hand, the results showed that the intensity of the warm-up has big influence on the performance. High intense warm-up without appropriate recover can cause drop in the result. More research needs to be done on this topic with many different conditions.
\end{abstract}

Keywords: swimming, warm-up, duration, intensity, performance

\section{Introduction}

In many sports disciplines the athlete should be prepared for the competition or training session on the best possible way. "A warm-up is a group of exercises performed immediately before activity, which helps the body to adjust from a state of rest to exercise" (Harris and Elbourn, 2002, p. 9). In this paper it will be discussed about the influence that prior exercise has on the performance. "The performance is defined as the ability to bring about some end result with maximum certainty and minimum outlay of energy, pr of time and energy" (Guthrie, 1952). 
The main goal of the good warm-up session is to give the opportunity to the athlete to perform his or her best during the performance. That means that warm-up sessions should be designed to increase muscle temperature, flexibility and motivation of the athlete (Leonard, 1992). For different kinds of sport activity there are different kinds of warm-up as prior exercise. However, it can be said that there are two different types of warm-up sessions for all activities: active warm-up and passive warm-up. Passive warm-up results with increasing of muscle temperature by some external factors such as hot showers and baths, saunas and heating pads. Compared to passive warm-up, active warm-up is result of physical activity and causes bigger physiological changes in athlete's body (Bishop, 2003).

There is no one standardized warm-up session that is recommended for all swimmers. An effective warm up session should be set for each athlete individually because every athlete is different. Moreover, different swimming events require different types of warm-up and the content of warm-up session before each competition should be carefully designed by swimming coaches, but the content should be discussed with the athlete as well (Lewin, 1979). Well designed warm-up session should prepare swimmer's cardiovascular, cardiorespiratory, musculoskeletal and neuromuscular system for high intense exercise (Harris and Elbourn, 2002). Two most important effects that warm-up have on swimmers are psychological and physiological effects.

Warm-up sessions before the competition are very important especially for the swimmers that have problems with high level of anxiety. "Anxiety is defined as unpleasant, consciously perceived feelings of tension and apprehension, with associated activation or arousal of the autonomic nervous system" (Spielberger, 1972). Athletes with high level of anxiety have negative feelings before some event and coaches must give them appropriate instructions about their warm-up. That is one of the ways of putting their attention to something else, not to negative self-talking to themselves. Self-talk before competition can be positive as well and can have some positive effect on the result (Leonard, 1992). However, if the self-talk is negative it can result with high level of anxiety and it is clear that cognitive anxiety can have big influence on the performance among athletes (Vickers, 2007). During that session swimmers are becoming familiar with the swimming pool and they have the opportunity to put their attention on all aspects of their race. Moreover, they have enough time during that session to carefully plan their races one more time, because that is one very important part of the overall preparation for the important race (Volcansek, 2002).

Physiological goal of warm-up sessions is to transform swimmers' body from resting state into the state in which can be performed competition. Before every exercise muscles are not prepared to start with exercise immediately (Harris and Elbourn, 2002; Hoffman, 2002). The main physiological goals of warm-up are to prepare body to deliver more oxygen to the muscles, and muscles to use that oxygen more rapidly (Maglischo, 2003). Also, warm-up sessions should increase flexibility of the muscles, blood flow through them and heart rate. The first thing that athletes can notice after a proper warm-up is that their muscles have higher temperature. Probably, that is the main reason why prior exercise is well known as warm-up. The increscent of muscle temperature result with increscent of muscle strength (Bergh and Ekblom, 1979). Moreover, there are some evidences that higher muscle temperature results with higher flexibility of the muscles for more than 20\% (Wright and Johns, 1960). Other, also very important physiological factor of prior exercise and performance as well is oxygen consumption. The results from some studies (Burnley et al., 2001) showed that prior exercise cannot significantly improve oxygen consumption, but after the warm-up, there will be more anaerobic capacities for the performance. Also the warm-up sessions before competitions can decrease the accumulation of lactic acid (Bishop, 2003). However, many authors states that physiological effects of warm-us do not last for a long period of time. They do not exist after 15-20 minutes after warm-up and also cannot be beneficial for reduction of lactic acid anymore (Leonard, 
1992). Because of this it is recommended to prolong warm-up session as close as it is possible to the event.

During the process of designing warm-up sessions, coaches should be aware of many parameters such as duration, intensity, content of the session and others. Intensity of the exercise shows how demanding the exercise is on the participant (Harris and Elbourn, 2002). The intensity of the exercise is correlated with lactate production. Many authors states that every exercise with intensity higher than $70 \%$ of athlete's $\mathrm{VO}_{2} \max$ increase the level of the lactic acid in the blood (Fratric, 2006). Because of that, authors and coaches suggest that the swimmers should avoid swimming with high intensity during the warm-up session before the competition. Short distance swimmers should consider doing hard $15 \mathrm{~m}, 25 \mathrm{~m}$ and 50 meters distance to establish race pace. Swimmers that swim longer distance races should use longer distance for establishing their pace such as 100 meters (Colwin, 1992). The precise answer on the question what is recommended duration and the amount of swimming that swimmers need to do for proper warm-up, the coaches and the researchers cannot give us. The amount of time that is required for warm-up session before competition is from 20 to 45 minutes (Maglischo, 2003). Every swimmer with longer experience in swimming can easily assess how much of swimming is enough for him or her to have decent warm-up (Colwin, 1992). Some researchers claim that 30 minutes is minimum required for doing all procedures for proper warm-up, while others think that everything that is longer duration than 30 minutes is waste of time. Swimming warm-up session before the race can be divided into a couple of separate parts. Chronologically, first, before entering the water all swimmers should do some flexibility exercises. That should make their bodies more flexible and prepare them for swimming. Swimming should start very easily, at $20 \%$ to $40 \%$ of maximal effort of swimming (Maglischo, 2003). The most of the warm-up session should be done at intensity from $30 \%$ to $50 \%$ of athlete's VO2max (ChwalbinskaMoneta and Hanninen, 1989). That sounds very reasonable because of the fact that high intense exercise can cause many physiological changes in the athlete's body that can result with dropping in the performance (Bishop, 2003; Wilkerson et al., 2004). The researchers and many coaches are agreed that effective swimming warm-up session should contain kicking, pulling, swimming stroke drills, full stroke swimming to warm up all muscle groups. All that should be contained in this part of warm-up session to rehearse swimmer's stroke mechanics. Other, very important part of every warm-up before the event is practicing starts and turns.

\section{Method}

The idea for this research study was to test short distance swimmers and to find out if there is any influence of different intensity and duration of warm up regimes on subsequent performance. There were three different types of warm up sessions: long (overall 3000 meters) and short duration warm up sessions (overall 1500 meters) and high intensity (overall 3000 meters) warm up session with same structure but higher intesity. After each warm up session swimmers were perform 100 meters as quickly as possible. The data that were collected during this study were the time of the performance on 100 meters and split time on 50 meters. Our dependent variables will be duration and intensity of warm up sessions. Eight male and four female participants took a part in this study. All of them were competitive swimmers aged $19-$ 26. All of them were engaged with four to six training sessions in the swimming pool per week. All the participants were regularly attempting training sessions at least three months before testing. For this type of study it was necessary to use ANOVA with Repeated Measures. This analyse were done for the split times after first 50 meters on the 100 meters performance and 100 metar time. In the results the researchers were looking for significant difference in the performance that swimmers achieved after those three warm up sessions. Statistical significance was set at $\mathrm{p}<0.05$. 


\section{Results}

The mean time of all twelve participants during first trial which represent the results that swimmers achieved on 100 meters performance after long duration warm-up session was 01:01:67. The mean time after short duration warm-up session was 01:01:73 and after high intensity warm-up 01:02:32 (Table 1).

Table 1.

The results after of 100 meters swimming performance - Descriptive Statistics

\begin{tabular}{ccccc}
\hline & Mean & $\begin{array}{c}\text { Std. } \\
\text { Deviation }\end{array}$ & $\mathrm{F}$ & $\mathrm{p}$ \\
\hline Trial 1 & $01: 01.666$ & $00: 06.918$ & & \\
Trial 2 & $01: 01.735$ & $00: 07.179$ & 8.75 & 0.02 \\
Trial 3 & $01: 02.321$ & $00: 06.988$ & & \\
\hline
\end{tabular}

The tests of Within Subjects Effects showed that there was significant difference between different conditions ( $F \operatorname{GG}(2,22)=8.75, \mathrm{p}=.002$ ). Pairwise Comparisons showed that the difference between trial 1 and trial 2 was not significant $(p=1)$. On the other hand the difference was significant between trial 1 and trial $3(\mathrm{p}=.02)$ and between trial 2 and trial 3 as well $(\mathrm{p}=.03)$ (Table 2).

Table 2.

The results of 100 meters swimming performance - Pairwise Comparisons

\begin{tabular}{ccccc}
\hline \multicolumn{5}{c}{ Mean } \\
(I) Trial (J) Trial & Difference (I-J) & Std. Error & Sig. \\
\hline 1 & 2 & -.069 & .105 & 1.000 \\
& 3 & $-.655^{*}$ & .202 & .024 \\
2 & 1 & .069 & .105 & 1.000 \\
& 3 & $-.586^{*}$ & .192 & .033 \\
3 & 1 & $.655^{*}$ & .202 & .024 \\
& 2 & $.586^{*}$ & .192 & .033 \\
\hline
\end{tabular}

The mean time of all twelve participants during first trial which represent the split time for the first 50 meters that swimmers achieved on 100 meters performance after long duration warm-up session was 00:29:58. The mean time of first 50 meters after short duration warm-up session was 00:29:72 and after high intensity warm-up 00:29:80 (Table 3). 
Influence of warm up sessions on swimmers' performance

Table 3.

The results after first 50 meters during swimming performance - Descriptive Statistics

\begin{tabular}{ccccc}
\hline & Mean & $\begin{array}{c}\text { Std. } \\
\text { Deviation }\end{array}$ & F & p \\
\hline Split 1 & $00: 29.582$ & 03.471 & & \\
Split 2 & $00: 29.726$ & 03.432 & 3.75 & 0.04 \\
Split 3 & $00: 29.808$ & 03.468 & & \\
\hline
\end{tabular}

The tests of Within Subjects Effects showed that there was significant difference between different conditions $(\mathrm{F} \mathrm{GG}(2,22)=3.74, \mathrm{p}=.04)$. Pairwise Comparisons showed that the difference between trial 1 and trial 2 was not significant $(\mathrm{p}=.44)$. Moreover, the difference between trial 2 and trial 3 was not significant $(\mathrm{P}=1)$, but the difference between trial 1 and trial 3 was significant $(\mathrm{p}=.03)$ (Table 4).

Table 4.

The results after first 50 meters during swimming performance - Pairwise Comparisons

\begin{tabular}{ccccc}
\hline $\begin{array}{c}\text { (I) } \\
\text { Trial }\end{array}$ & $\begin{array}{c}\text { T) } \\
\text { Trial }\end{array}$ & $\begin{array}{c}\text { Mean } \\
\text { Difference (I-J) }\end{array}$ & Std. Error & Sig. \\
\hline 1 & 2 & -.143 & .092 & .437 \\
& 3 & $-.225^{*}$ & .074 & .033 \\
2 & 1 & .143 & .092 & .437 \\
& 3 & -.082 & .084 & 1.000 \\
3 & 1 & $.225^{*}$ & .074 & .033 \\
& 2 & .082 & .084 & 1.000 \\
\hline
\end{tabular}

\section{Discussion}

Swimming warm-up sessions are one of the essential things in all preparation for the performance during some swimming competition (Maglischo, 2003; Volcansek 2002). The results showed that there was not any significant difference in the performance between long duration and short duration warm-up session $(\mathrm{p}=.1)$. Although the duration of long duration warm-up session was twice longer compared to short duration session the difference between them was not significant. However, the intensity of both sessions was at the same level. The difference in split times after first 50 meters during performance was not significant as well $(\mathrm{p}=.44)$. From those data it can be concluded that for the short-term races it is not necessary to do warm-up session that has more than 1500 meters. However, the coaches should be careful with those results especially because there are some evidences that long-term races require longer duration of warm-up sessions (Maglischo, 2003; Volcansek, 2002). In this case, the short term swimmers performed 100 meters swim very similar after both, long and short duration warm-up sessions. However, these results just suggest that there is no difference between long duration 
and short duration warm-up at the same level of intensity. It can be said that easy swimming is very beneficial and can improve short term performance (Genovely and Stanford, 1982; Houmard et al., 1991; Maglischo, 2003) compared to high intense warm-up in this study and no warm-up conditions and dry-land warm-ups in the previous studies (Bishop, 2003; Romney and Nethery, 1993). When comparing performance time after long duration warm-up and after warm-up session with high intensity there was significant difference $(\mathrm{p}=.02)$. Furthermore, the difference was significant between short duration and high intensity warm-up sessions $(p=.03)$. These data are strong evidence that during this study, the high intensity warm up session and short recovery period had big influence on the short-term swimming performance. Both, short duration session and high intensity warm-up session had the same amount of swimming - 1500 meters. However, the difference in intensity was great. Observing these data it can be noticed that high intensity warm-up session was too intense. Also, the recovery period of 5 minutes between that session and performance obviously was not long enough.

Some previous studies showed that very short recovery time between warm-up session and the performance can cause dropping in the performance if the warm-up session was at higher level of intensity (Burnley et al., 2005; Ferguson et al., 2007). As many authors suggest, for removing lactic acid from the blood it is necessary to pass some time or to spend that time in easy swimming or massage (Bishop, 2003; Hoffman, 2002; Maglischo, 2003). In this case, the swimmers had only 200 meters of easy swimming and 5 minutes time for recovery before the performance. It is suggested that warm-up sessions before swimming performance should be prolonged as much closer to the race as it is possible the recovery period of 5 minutes was appropriate (Leonard, 1992). In this case the problem was the high intensity during most of the time of the high intense warm-up session. High intensity swimming as prior exercise to the race is recommended only for establishing correct race pace during warm-up. However, during high intensity warm up session in this study that was not the case. As some authors suggest the time period between high intense pace practicing and performance should be at least 20 minutes (Maglischo, 2003; Volcansek, 2002), what in this study was not the case. One of the most important things during designing a proper warm-up session is the combination of the intensity of the session and the duration of the recovery period before the performance (Hoffman, 2002; Palmer et al., 2009; Vanhatalo and Jones, 2009; Volcansek, 2002). So far, by observing the data from this study it is possible to say that high intensity played significant role in dropping in the performance. The best split time after first 50 meters on the 100 meters performance, swimmers had during the first trial which was performed after long duration swimming session. However, comparing to trial 2 that was performed after short duration session the difference in the time was not significant $(\mathrm{p}=.43)$. But, as in overall performance the difference in split times was significant between trial 1 and trial $3(\mathrm{p}=.03$ ). That means the swimmers have performed first 50 meters after long duration session much faster compared to first 50 meters after high intense warm-up. On the other hand, the interesting finding is that split time after first 50 meters was very similar during trial 2 and trial 3 . In this study, first time there is not significant difference between performance after one low intense warm-up and high intense warm-up $(p=1)$. However, that means that last 50 meters were significantly better performed after short duration session with low intensity compared to high intense warm-up. Here, the conclusion can be that the level of the lactic acid in the blood significantly increased and caused the drop in the performance during last 50 meters during last trial. Even it cannot be said for sure, because there are no provided data about the level of lactic acid in the blood, the high intense warm-up without appropriate recovery caused drop in the performance on 100 meters race, especially during last 50 meters. To compare the level of the lactic acid during the race the best option will be longterm swimming performance. There are evidences that the lactate level in the blood is dropping faster after performance that was done after proper swimming warm-up session (Bishop, 2003; Genovely and Stanford, 1982; Robergs et al., 1990). Now, with the data for 100 meters performance and without lactate blood sample it is not clear how duration of the session and the amount of swimming can influence on the performance. In the case of short term performance 
Influence of warm up sessions on swimmers' performance

the duration of the warm-up session and the amount of swimming during it did not show any significant influence on the result.

\section{Conclusion}

It is established that the warm-up session prior short term swimming performance is benefitial and can improve swimming performance (Bishop, 2003; Maglischo, 2003). However, there are still many questions about warm-up sessions that should be answered in the future. It is still not $100 \%$ clear what should be appropriate content of every warm up session, how great should be the total amount of swimming during those sessions and how intense those sessions should be. Furthermore, there are no many clear evidences about the recovery period between warm-up and the performance. From the results from this study and many others already existing evidences it can be said that the recovery period between high intense swimming during warmup and performance should be long enough or there is going to be visible drop in the results (Bishop, 2003; Ferguson et al., 2007; Palmer et al., 2009). In the case of this study, very short recovery period after high intense swimming caused drop in the performance, compared to the 100 meters swim performed after sessions with low intensity swimming.

One of the key findings from this study was non-significant difference in the performance performed after long duration and short duration warm-up. However, these results should be interpreted carefully and the readers should be aware that in this study was tested short-term swimming performance only. That finding can have its role in planning of the warm-up sessions before swimming races, but before the training sessions as well. If something can significantly improve performance it can have very useful role in making training sessions more productive.

Good warm-up session should be planed for every swimmer individually, because different strokes, different distances, and different persons need different warm-up sessions. That is the only way for the athletes to be well prepared for the performance. The best warm-up session for some athlete is the session that gives the best results to that athlete, even if that warmup session may be does not look very best and does not have all important findings implemented inside.

This study has revealed some interesting findings but many research need to be done in the future. If the researchers and sports scientists want to improve swimming performance and to move the limits in the modern swimming they should pay a lot of attention on the prior exercise. Especially, more research is needed with high intense parts of the warm-up sessions. Those sessions should be as much realistic and similar to those during competitions as it is possible. Suggestion for further research projects can be the testing of high intense part of swimming sessions at different part of the session and different recovery period before the performance. A lot of attention should be putted on the recovery period between high intense part of the warm-up session and the performance. Duration and the content of that period should be tested. Many important findings the researchers have already found out, but still there is a gap in the knowledge. It is sure that in the future swimming warm-up sessions will have some different structure, but that structure will not be the result of only some new findings, but the result of already existing evidences improved with some new findings. 


\section{References}

Bishop, D. (2003). Warm up II: Performance changes following active warm up and how to structure the warm up. Sports Medicine, 33(7), 483-498.

Chwalbinska-Moneta, J., \& Hanninen, O. (1989). Effects of active warm-up on thermoregulatory, circulatory, and metabolic responses to incremental exercise in endurance-trained athletes. International Journal of Spots Medicine, 10(1), 25-29.

Colwin, C. M. (1992). Swimming Into the $21^{\text {st }}$ Century. Champaign, IL: Human Kinetic.

Ferguson, C., Whipp, B. J., Cathcart, A. J., Rossiter, H. B., Turner, A. P., \& Ward, S. A. (2007). Effects of prior very-heavy intensity exercise on indices of aerobic function and highintensity exercise tolerance. Journal of Applied Physiology, 103, 812-822.

Fratrić, F. (2006). Teorija i metodika sportskog treninga. [Theory and Methodics of Sport Training]. Novi Sad: Pokrajinski zavod za sport.

Genovely, H., \& Stanford, B. A. (1982). Effects of prolonged warm-up above and below the anaerobic threshold on maximal performance. European Journal of Applied Physiology, $28,323-330$.

Guthrie, E. R. (1952). The Psychology of Learning. New York: Harper and Row.

Harris, J., \& Elbourn, J. (2002). Warming Up and Cooling Down. Champaign, IL: Human Kinetic.

Hoffman, J. (2002). Physiological Aspects of Sport Training and Performance. Champaign, IL: Human Kinetic.

Houmard, J. A., Johns, R. A., Smith, L. L., Wells, J. M., Kobe, R. W., \& McGoogan, S. A. (1991). The effects of warm-up responses to intense exercise. International Journal of Sports Medicine, 12, 480-483.

Leonard, J. (1992). Science of Coaching: Swimming. Champaign, IL: Human Kinetic.

Lewin, G. (1979). Swimming. Berlin: Sportverlag.

Maglischo, E. W. (2003). Swimming Fastest: The essential reference on technique, training, and program design. Champaign, IL: Human Kinetic.

Palmer, C. D., Jones, A. M., Kennedy, G. J., \& Cotter, J. D. (2009). Effects of prior heavy exercise on energy supply and $4000 \mathrm{~m}$ cycling performance. Medicine Science and Sports Exercise, 41, 221-229.

Romney, N. C., \& Nethery, V. M. (1993). The effect of swimming and dryland warm-ups on 100 -yard freestyle performance in collegiate swimmers. Journal of Swimming Research, 9, 5-9.

Robergs, R. A., Costill, D. L., Fink, W. J., Williams, C., Pascoe, D. D., Chwalbinska-Moneta, J., et al. (1990). Effects of warm-up on blood gases, lactate and acid-base status during sprint swimming. International Journal of Sports Medicine, 11(4), 273-278.

Spielberger, C. S. (1972). Anxiety: Current Trends in Theory and Research. New York: Academic Press.

Vanhatalo, A., \& Jones, A. M. (2009). Influence of prior sprint exercise on the parameters of the all-out critical power test in men. Exercise Physiology, 94, 255-263.

Vickers, J. N. (2007). Perception, Cognition, and Decision Training. Champaign, IL: Human Kinetic. 
Volčanšek, B. (2002). Bit plivanja. [The Essence of Swimming]. Zagreb: Kineziološki fakultet Sveučilišta u Zagrebu.

Wilkerson, D. P., Koppo, K., Barstow, T. J., \& Jones, A. M. (2004). Effect of prior multiple sprint exercise on pulmonary $\mathrm{O} 2$ uptake kinetics following the onset of perimaximal exercise. Journal of Applied Physiology, 97, 1227-1236.

Wright, V., \& Johns, R. J. (1960). Physical factor concerned with the stiffness of normal and diseased joints. Bulletin of Johns Hopkins Hospital, 106, 215-231. 